\title{
Cost-Effectiveness Evaluation of a Remote Monitoring Programme Including Lifestyle Education Software in Type 2 Diabetes: Results of the Educ@dom Study
}

\author{
Michael Mounié (D) · Nadège Costa $\cdot$ Pierre Gourdy $\cdot$ Christelle Latorre $\cdot$ Solène Schirr-Bonnans · \\ Jean-Marc Lagarrigue $\cdot$ Henri Roussel · Jacques Martini · Jean-Christophe Buisson • Marie-Christine Chauchard · \\ Jacqueline Delaunay · Soumia Taoui · Marie-France Poncet • Valeria Cosma · Sandrine Lablanche • \\ Magali Coustols-Valat · Lucie Chaillous · Charles Thivolet · Caroline Sanz · Alfred Penfornis · Benoît Lepage • \\ Hélène Colineaux · Hélène Hanaire · Laurent Molinier · Marie-Christine Turnin on behalf of the Educ@dom \\ Study Group
}

Received: December 3, 2021 / Accepted: January 18, 2022 / Published online: February 8, 2022

(C) The Author(s) 2022, corrected publication 2022

\section{ABSTRACT}

Introduction: Telemedicine programs using health technological innovation to remotely monitor the lifestyles of patients with type 2 diabetes (T2D) can improve glycaemic control

The members of the Educ@dom Study Group Collaborators are listed in the Acknowledgements section.

Supplementary Information The online version contains supplementary material available at https:// doi.org/10.1007/s13300-022-01207-1.

M. Mounié $(\bowtie) \cdot N$. Costa · C. Latorre ·

S. Schirr-Bonnans · L. Molinier

Health-Economic Unit, Medical Information

Department, University Hospital, Toulouse, France

e-mail: mounie.m@chu-toulouse.fr

P. Gourdy · J. Martini · M.-C. Chauchard .

J. Delaunay · S. Taoui · H. Hanaire - M.-C. Turnin

Department of Diabetology, Metabolic Diseases and

Nutrition, Toulouse University Hospital, Toulouse,

France

P. Gourdy · H. Hanaire

Institute of Metabolic and Cardiovascular Diseases, UMR1297 INSERM/UPS, Toulouse University,

Toulouse, France

J.-M. Lagarrigue

MSA Midi-Pyrénées Nord, 180 Avenue Marcel UNAL, 82000 Montauban, France and thus reduce the incidence of complications as well as management costs. In this context, an assessment was made of the 1-year and 2-year cost-effectiveness of the EDUC@DOM telemonitoring and tele-education program.

Methods: The EDUC@DOM study was a multicentre randomized controlled trial conducted between 2013 and 2017 that compared a telemonitoring group (TMG) to a control group (CG) merged with health insurance databases to extract economic data on resource consumption. Economic analysis was performed from the payer perspective, and direct costs and

\author{
H. Roussel \\ CNAM, DRSM Occitanie, 2 rue Georges Vivent, \\ 31082 Toulouse, France \\ J. Martini · M.-C. Chauchard \\ DIAMIP Network, Toulouse, France \\ J.-C. Buisson \\ ENSEEIHT, Toulouse, France \\ M.-F. Poncet \\ Claude Bernard Clinic, Albi, France \\ V. Cosma \\ Hospital Center, Nîmes, France \\ S. Lablanche \\ University Hospital, Grenoble, France \\ M. Coustols-Valat \\ Ambroise Paré Clinic, Toulouse, France
}


indirect costs were considered. The clinical outcome used was the intergroup change in glycated haemoglobin (HbA1c) levels from baseline. Missing economic data were imputed using multiple imputation, and fitted values from a generalized linear mixed model were used to calculate the incremental cost-effectiveness ratio (ICER). Bootstrapped 95\% confidence ellipses were drawn in the costeffectiveness plan.

Results: The main analysis included data from 256 patients: 126 in the TMG and 130 in the CG. Incremental costs over 1 and 2 years were equal to $€ 2129$ and $€ 5101$, respectively, in favour of the TMG. Once imputed and adjusted for confounding factors, the TMG trends to a $21 \%$ cost decrease over 1 and 2 years of followup $(0.79$ [0.58; 1.08], $p=0.1452$ and 0.79 [0.61; 1.03], $p=0.0879$, respectively). The EDUC@DOM program led to a $€ 1334$ cost saving and a 0.17 decrease in HbA1c over 1 year and a $€ 3144$ cost saving and a 0.14 decrease in HbA1c over 2 years. According to the confidence ellipse, EDUC@DOM was a cost-effective strategy.

Conclusion: This study provides additional economic information on telemonitoring and tele-education programs to enhance their acceptance and promote their use. In the light of this work, the EDUC@DOM program is a costsaving strategy in T2D management.

L. Chaillous

University Hospital, Nantes, France

C. Thivolet

University Hospital, Lyon, France

C. Sanz

Pasteur Clinic, Toulouse, France

A. Penfornis

Sud Francilien Hospital, Corbeil-Essonnes, and Paris-

Saclay University, Corbeil-Essonnes, France

B. Lepage $\cdot$ H. Colineaux

Department of Epidemiology, University Hospital, Toulouse, France

M. Mounié · N. Costa · B. Lepage $\cdot$ H. Colineaux L. Molinier

CERPOP, INSERM - University Toulouse III Paul

Sabatier, Toulouse, France
Trial registration: This trial was registered in the Clinical Trials Database on 27 September 2013 under no. NCT01955031 and bears IDRCB no. 2013-A00391-44.

Keywords: Cost-effectiveness; Type 2 diabetes; Telemonitoring; Tele-education; EDUC@DOM; Economic assessment; Lifestyle management

\section{Key Summary Points}

This work assesses the cost and the costeffectiveness of a telemonitoring and teleeducation program that routinely gathers data on weight, physical activity and diet in addition to glycaemia control in order to improve the monitoring of type 2 diabetes patients.

This work is based on RCT in addition to accurate data on resource consumption, which allow the impact of intervention to be assessed precisely.

This work points out a trend for cost savings by the telemonitoring group over 1-year and 2-year periods, despite the related program cost.

It is concluded that the EDUC@DOM program is cost effective, with a high probability of being a dominant strategy.

\section{INTRODUCTION}

Current guidelines advocate promoting self-education and lifestyle changes to improve type 2 diabetes (T2D) management [1]. Reinforcing a patient's therapeutic education, notably in relation to nutrition and physical activity, by means of a telemonitoring device is thought to lead to better glycaemic control [2, 3]. In addition, studies have highlighted a strong relationship between impaired glycaemic control and the patient's morbidity and mortality $[4,5]$. Such a bad prognosis is mainly due to the increased incidence and progression of diabetes- 
related complications, which can thereby be avoided with personalized diabetes management that improves glycaemic control $[6,7]$. While efficient therapeutic interventions are available, it is hard to obtain optimal patient self-governance and a beneficial metabolic effect in the long term $[8,9]$. In this context, health technological innovation can help patients to remotely monitor their lifestyle using a health-related object that is connected [10].

Telemonitoring or tele-education strategies are still struggling to prove their cost-effectiveness in the management of diabetes, largely due to a scarcity of data and a general focus on telephone- and internet-based interventions [11-13]. Health economic studies of innovative tools that aim to optimize diabetes management are crucial to enhancing their acceptance by health authorities in the long term. Furthermore, diabetes-related complications lead to substantial additional costs, as assessed in Sweden in 2016 ( $€ 1317$ per patient) [14], while a systematic review in France and Germany in 2020 found that costs resulting from complications were the main cost component [15]. Diabetic retinopathy, diabetic kidney disease and diabetic foot ulcer are among the main complications studied, with annual costs of $€ 2297$, $€ 2843-3908$, and $€ 10,604$, respectively [16]. Improving glycaemic control and reducing the incidence of complications may thus lead to cost savings for these strategies, particularly in the long-term setting.

A report was recently released on the effectiveness of the EDUC@DOM telemonitoring and tele-education program in T2D management [17]. This randomized controlled trial (RCT) was designed to assess new at-home education software that supports lifestyle modification in addition to a connected object, thus offering an integrated telemonitoring program. To our knowledge, this program is the first to support a personalized nutritional education program using artificial intelligence. For people with T2D, using the EDUC@DOM program for a 1 -year period led to a decrease in $\mathrm{HbA1c}$ that was estimated to lie at the significant boundary $(p=0.06)$. This improvement in glycaemic control was significant in the frequent user subgroup. In this work, it is hypothesized that the EDUC@DOM program is cost effective for a 1 -year period and notably so for a 2 -year period, where it tends to be a dominant strategy. In this context, the aim was to estimate the cost-effectiveness of the EDUC@DOM telemonitoring and tele-education program over 1- and 2-year follow-up periods.

\section{METHODS}

\section{Study Design and Patients}

The EDUC@DOM trial was an open-label, multicentre RCT conducted at 16 French investigation sites between November 2013 and May 2017 that aimed to compare a telemonitoring group (TMG) to a control group (CG). The subjects enrolled in the study were 18 years or older, had a documented medical history of T2D with or without insulin treatment, and had a recent $\mathrm{HbA1c}$ value of between $6.5 \% \quad(48 \mathrm{mmol} / \mathrm{mol})$ and $10 \%$ (86 mmol/mol) [18]. The TMG received, for a 1 -year period, a tablet in which biomedical data sensors were combined with three educational software programs (Nutri-Kiosk, ActiKiosk, Nutri-Educ). These software programs combined self-learning quizzes, support in starting physical activity, and a personalized nutritional education application that used artificial intelligence algorithms to design a perfect meal and improve their nutritional balance [19-23]. The T2D patients who made up the CG did not receive the telemonitoring and tele-education program and received the usual care. Patients were randomized into the TMG and CG groups, applying stratification by $\mathrm{HbA1c}$ level at inclusion using a $7.5 \%$ threshold.

The patients' clinical data collected in the trial were merged with healthcare consumption data from health insurance databases at the regional level. These included individuals belonging to the general scheme and the agricultural scheme, corresponding to $81 \%$ of the French population [24]. These regional medical 
and administrative databases exhaustively collect data on healthcare consumption and corresponding reimbursements such as those in the national database (i.e. The National System of Health Data), which has been available since 2017, after the end of this study. Nevertheless, less detail is given in the regional databases, especially for inpatient care, for which diagnoses were not available. They gather demographic data (i.e. age, sex, vital status, and date of death), ambulatory care reimbursement data (including drug dispensing) and inpatient care data [25]. Patients without any care for 1 year were considered to have missing data. Clinical and economic data were merged using a pseudonym based on name, surname, birthdate and gender, in accordance with French legislation.

\section{Setting and Perspective}

The economic analysis was performed from the French National Health Insurance (FNHI) perspective and focused on direct medical costs, represented by inpatient and outpatient care costs, and direct non-medical costs, represented by transportation costs. In addition, costs associated with the disability pension and daily allowance were available. Outpatient care costs corresponded to the cost of visits, medical and paramedical procedures, outpatient drugs and medical equipment. Costs were estimated by multiplying the number of resources used by the corresponding reimbursement tariff and rate given by the FNHI. In France, $100 \%$ of the disease-related cost is funded by the FNHI if the disease belongs to a long-term disease scheme, such as diabetes. Other healthcare consumption is reimbursed, generally at a rate of $60-80 \%$, depending on the care provided.

Resource consumption and related costs were identified during a 2-year period from the patient inclusion date. We were not able to differentiate costs associated with T2D management from the costs related to other comorbidities, so we focused on all reimbursed care. The cost of the EDUC@DOM program was assessed as being equal to $€ 1015$ over 1 year and was based on the FNHI tariff that had settled it in the context of an experiment on telemedicine programs.

\section{Clinical and Economic Outcomes}

Our goal was to estimate the incremental costeffectiveness ratio (ICER), defined as the incremental mean cost between TMG and CG divided by the incremental mean effectiveness between groups. This ratio represents the estimated monetary value that must be expended to gain one unit of effectiveness [26]. This study focused on assessing the ICER at both 1 and 2 years of follow-up.

The clinical outcome used in the cost-effectiveness analysis was the intergroup change in HbA1c levels. Although the evaluated program was only used in the first year, it was hypothesized that glycaemic control remained better during the second year in the TMG, leading to increased cost savings. Economic outcomes were the total cumulative costs over the 1- and 2 -year periods. No discount rate was applied. Costs were expressed so as to correspond to 2020 prices using the French Consumer Price Index (CPI) from the Organisation for Economic Co-operation and Development (OECD).

\section{Statistical Analyses}

Descriptive analysis was realized on baseline characteristics of the T2D patients using the mean and standard deviation or the frequency and percentage, and group comparison was done using the Z-test or the $\chi^{2}$ test when appropriate.

In order to access all patient-related clinical data, and to implement adjustment models in particular, the focus was on the population used in clinical multivariate analysis. Economic data were not available for part of our population, mainly due to the coverage of the health insurance database used (i.e. 86\%). It was hypothesized that this incomplete coverage would not impact the missingness mechanism in term of resource use and costs, and that turning to a missing at random mechanism would allow imputation methods to be used. 
In this context, descriptive analyses of costs were performed on the available economic data according to the treatment arms, the main cost components were described using mean, biascorrected and accelerated 95\%-bootstrapped confidence intervals, and incremental costs and the non-parametric Mann-Whitney Wilcoxon test were used to assess cost differences between groups [27]. A multiple imputation with predictive mean matching method was used to impute missing data [28]. Age, gender, group, obesity, undergoing insulin and centre were used as the imputation variables. Effectiveness was adjusted by a cofounding factor, and a fitted value was used in the analyses. To ensure that the estimate of the ICER was correct, a generalized linear mixed model was used to assess the adjusted effect of EDUC@DOM on cost, and fitted values for both numerator and denominator were used in the ICER calculation. Similar variables were used for imputation and for the model. Finally, using bootstrap replication on mean cost and mean effectiveness, the 95\% confidence ellipse graphically representing the $95 \%$ credible region of the ICER was drawn in the cost-effectiveness plane (CEP); this is considered a probabilistic sensitivity analysis $[29,30]$. The CEP is divided into four quadrants. ICERs with negative values are in the southeast and northwest quadrants and do not need to be interpreted because the new strategy is less costly and more effective (i.e. a dominant strategy) or costlier and less effective (i.e. a dominated strategy) compared to the reference strategy. ICERs with positive values are in the southwest and northeast quadrants, and those in the northeast quadrant are generally compared to the collective willingness to pay (WTP) threshold, which represents the maximum monetary value that a decision-maker might be willing to pay for a particular unit change in the outcome.

\section{Statement of Ethics Compliance}

All type 2 diabetes patients participating in this research received verbal and written information and were given the opportunity to ask any questions to help them understand the study.
They signed a voluntary informed consent form before the research began. This study was submitted to the South-West and French Overseas Territories Research Ethics Committee and received a favourable opinion from the REC on $27 / 05 / 2013$. The study was performed in accordance with the Helsinki Declaration of 1964 and its later amendments. Additionally, authorization to access healthcare consumption using healthcare insurance databases was obtained from the Informatics and Liberty National Commission (authorization number: 913263).

\section{RESULTS}

Full clinical data were available for 256 study participants: 126 in the TMG and 130 in the CG. Only two differences were notable from the baseline characteristics at the 0.10 level of significance, with a higher proportion of peripheral neuropathy observed in the control group $(11.1 \%$ vs $22.3 \%, p=0.019)$ and a higher proportion of obesity observed in the TMG $(68.3 \%$ vs $57.7 \%, p=0.093)$. The difference in obesity was highlighted, despite having a significance of $10 \%$, because it usually impacts resource consumption and costs through related complications (Table 1).

\section{Economic Analysis}

Complete economic data were available for 178 (69.5\%) and 168 (65.6\%) patients over the 1and the 2-year periods, respectively. The total incremental mean cost was equal to $€ 2129$ and $€ 5101$ over the 1-year and 2-year periods, respectively, favouring the TMG despite the specific cost of the EDUC@DOM program itself (Table 2). Total incremental costs were mainly driven by medication costs, inpatient care costs and daily allowance or disability pension costs. No cost associated with the daily allowance or disability pension was noticed in the second year. Nevertheless, because of the drastically high intragroup cost variability in addition to the limited population size, these results were not significant due to missing data. Once imputed and adjusted, the TMG tended to a 
Table 1 Baseline patient characteristics, $n=256$

\begin{tabular}{|c|c|c|c|c|c|c|c|}
\hline$\overline{\text { Gender }}$ & \multicolumn{2}{|c|}{ Total $(n=256)$} & \multicolumn{2}{|c|}{ TMG $(n=126)$} & \multicolumn{2}{|c|}{ Control $(n=130)$} & $p$ \\
\hline Male & 162 & $63.3 \%$ & 81 & $64.3 \%$ & 81 & $62.3 \%$ & 0.796 \\
\hline Female & 94 & $36.7 \%$ & 45 & $35.7 \%$ & 49 & $37.7 \%$ & \\
\hline \multicolumn{8}{|l|}{ Age (years) } \\
\hline Mean and SD & 59.6 & 9.6 & 59.8 & 9.1 & 59.3 & 10.1 & 1 \\
\hline \multicolumn{8}{|l|}{ Randomization stratum } \\
\hline Baseline HbA1c < 7.5\% & 120 & $46.9 \%$ & 59 & $46.8 \%$ & 61 & $46.9 \%$ & 1 \\
\hline Baseline $\mathrm{HbAlc} \geq 7.5 \%$ & 136 & $53.1 \%$ & 67 & $53.2 \%$ & 69 & $53.1 \%$ & \\
\hline \multicolumn{8}{|l|}{ Baseline HbAlc } \\
\hline Mean and SD & 7.8 & 0.8 & 7.8 & 0.8 & 7.8 & 0.8 & 1 \\
\hline \multicolumn{8}{|l|}{ Diabetes complications } \\
\hline No & 118 & $46.1 \%$ & 61 & $48.4 \%$ & 57 & $43.8 \%$ & 0.531 \\
\hline Yes & 138 & $53.9 \%$ & 65 & $51.6 \%$ & 73 & $56.2 \%$ & \\
\hline \multicolumn{8}{|l|}{ Details of complications } \\
\hline Retinopathy & 41 & $16.0 \%$ & 16 & $12.7 \%$ & 25 & $19.2 \%$ & 0.172 \\
\hline Diabetic kidney disease & 68 & $26.6 \%$ & 36 & $28.6 \%$ & 32 & $24.6 \%$ & 0.681 \\
\hline Peripheral neuropathy & 43 & $16.8 \%$ & 14 & $11.1 \%$ & 29 & $22.3 \%$ & 0.019 \\
\hline Vegetative neuropathy & 10 & $3.9 \%$ & 4 & $3.2 \%$ & 6 & $4.6 \%$ & 0.749 \\
\hline Coronary heart disease & 47 & $18.4 \%$ & 28 & $22.2 \%$ & 19 & $14.6 \%$ & 0.147 \\
\hline Cerebrovascular disease & 11 & $4.3 \%$ & 3 & $2.4 \%$ & 8 & $6.2 \%$ & 0.217 \\
\hline Lower limb artery disease & 25 & $9.8 \%$ & 16 & $12.7 \%$ & 9 & $6.9 \%$ & 0.14 \\
\hline Diabetic foot ulcer & 8 & $3.1 \%$ & 4 & $3.2 \%$ & 4 & 3.1 & 1 \\
\hline \multicolumn{8}{|l|}{ Duration of diabetes } \\
\hline$<5$ years & 29 & $11.3 \%$ & 15 & $11.9 \%$ & 14 & $10.8 \%$ & 0.952 \\
\hline $5-15$ years & 126 & $49.2 \%$ & 61 & $48.4 \%$ & 65 & $50.0 \%$ & \\
\hline$\geq 15$ years & 101 & $39.5 \%$ & 50 & $39.7 \%$ & 51 & $39.2 \%$ & \\
\hline \multicolumn{8}{|l|}{ Insulin therapy } \\
\hline No & 76 & $29.7 \%$ & 37 & $29.4 \%$ & 39 & $30.0 \%$ & 1 \\
\hline Yes & 180 & $70.3 \%$ & 89 & $70.6 \%$ & 91 & $70.0 \%$ & \\
\hline \multicolumn{8}{|l|}{ BMI $\left(\mathrm{kg} / \mathrm{m}^{2}\right)$} \\
\hline Mean and SD & 31.9 & 5.3 & 32.5 & 5.4 & 31.3 & 5.2 & 1 \\
\hline \multicolumn{8}{|l|}{ Waist circumference } \\
\hline Mean and SD & 91.8 & 16.8 & 93.4 & 17.3 & 90.2 & 16.2 & 1 \\
\hline
\end{tabular}


Table 1 continued

\begin{tabular}{|c|c|c|c|c|c|c|c|}
\hline & \multicolumn{2}{|c|}{ Total $(n=256)$} & \multicolumn{2}{|c|}{ TMG $(n=126)$} & \multicolumn{2}{|c|}{ Control $(n=130)$} & \multirow[t]{2}{*}{$p$} \\
\hline \multicolumn{7}{|c|}{ Obesity $\left(\mathrm{BMI} \geq 30 \mathrm{~kg} / \mathrm{m}^{2}\right)$} & \\
\hline No & 95 & $37.1 \%$ & 40 & $31.7 \%$ & 55 & $42.3 \%$ & 0.093 \\
\hline Yes & 161 & $62.9 \%$ & 86 & $68.3 \%$ & 75 & $57.7 \%$ & \\
\hline
\end{tabular}

Numbers and percentages are shown unless otherwise stated

$T M G$ telemonitoring group, $S D$ standard deviation

$21 \%$ cost decrease over 1 and 2 years $(0.79$ [0.58; $1.08], p=0.1452$ and $0.79 \quad[0.61 ; 1.03]$, $p=0.0879$; respectively). Undergoing treatment with insulin and obesity were associated with a significant cost increase, ranging from 34 to $60 \%$ over the first and second periods (Table 3 ).

\section{Cost-Effectiveness Analysis}

The mean imputed and adjusted costs over the 1-year period in the TMG and CG were equal to $€ 11,735$ and $€ 13,069$, respectively, while the mean effectiveness values were equal to 7.50 and 7.67 (Table 4). Over the 1-year period, EDUC@DOM led to a $0.17 \%$ decrease in HbA1c and a $€ 1334$ cost saving. As observed in the CEP, most of the bootstrapped ICER replications and the confidence ellipse were in the southeast quadrant; none were in the northwest quadrant (Fig. 1). Furthermore, $87.2 \%$ of the bootstrap replications were within the southeast quadrant. Altogether, these data indicate that EDUC@DOM is a cost-effective strategy and has a high probability of being a dominant strategy over the first year.

The mean imputed and adjusted costs over the 2-year period in the TMG and CG were equal to $23,343 €$ and $26,487 €$, respectively, while the mean effectiveness values were equal to 7.59 and 7.73. Over the 2-year period, EDUC@DOM led to a $0.14 \%$ decrease in HbA1c and a $3144 €$ cost saving. Similarly, most of the confidence ellipse was in the southeast quadrant, and none of it was in the northeast quadrant, with $94.5 \%$ of the bootstrap replications within the southeast quadrant. EDUC@DOM thus appears to have been a cost-effective strategy over the 2-year follow-up period, and can be considered a dominant strategy with a high probability.

\section{DISCUSSION}

The present cost analysis demonstrated large cost differences between the two groups, with cost savings of $€ 2129$ and $€ 5101$ over 1 year and 2 years, respectively, in the TMG. Nevertheless, due to the huge variation in the cost of T2D patient management at the individual level, these differences were not significant. The main between-group cost differences came from both inpatient care and medication. On the one hand, half of our population already had complications at the baseline, and the inpatient care cost reduction may be linked to a lower rate of complications due to better patient management with reinforced glycaemic monitoring. On the other hand, the large differences in medication cost may be explained by improved glycaemic control in the TMG group, resulting from beneficial changes in dietary management and physical activity. Such lifestyle improvements notably led to a decrease in treatment consumption (a reduction in either the dosage or number of drugs), which certainly contributed to a slight HbA1c decrease and thus a lower management cost.

Once imputed and adjusted, TMG tended to a $20 \%$ cost reduction, particularly over the 2 -year period $(0.79[0.61 ; 1.03], p=0.0879)$. A significant $(p=0.06)$ between-group difference in glycaemic control has been previously shown, meaning that a trend for HbA1c diminution occurs in the TMG [17]. In this context, a cost-effectiveness analysis, rather than a cost-minimization analysis, is 
Table 2 Cost description for the first year $(n=178)$, the second year, and the two-year period $(n=168)$

First year costs, $n=178$ :

\begin{tabular}{|c|c|c|c|c|}
\hline Main cost components & $\begin{array}{l}\text { TMG } N=86 \\
\text { Mean CI }(95 \%)\end{array}$ & $\begin{array}{l}\text { CG } N=92 \\
\text { Mean CI }(95 \%)\end{array}$ & Incremental cost & $p$ \\
\hline Hospitalizations & $2992[1790 ; 6452]$ & $3688[2406 ; 6623]$ & -689 & 0.118 \\
\hline Consultations & $419[329 ; 611]$ & $505[383 ; 761]$ & -86 & 0.357 \\
\hline Medical acts & $668[493 ; 1031]$ & $827[599 ; 1350]$ & -159 & 0.531 \\
\hline Paramedical act & $298[194 ; 521]$ & $548[314 ; 958]$ & -250 & 0.227 \\
\hline Medication & $1876[1421 ; 2967]$ & $3033[2087 ; 5233]$ & -1157 & 0.170 \\
\hline Medical devices & $987[710 ; 1438]$ & $1096[763 ; 1667]$ & -109 & 0.888 \\
\hline Transportation & $172[84 ; 358]$ & $367[99 ; 1572]$ & -195 & 0.565 \\
\hline Daily allowance and disability pension & $2557[1390 ; 4313]$ & $3056[1838 ; 6135]$ & -499 & 0.795 \\
\hline EDUC@DOM & 1015 & 0 & 1015 & \\
\hline Total & $10,991[8467 ; 15768]$ & $13,120[9649 ; 21824]$ & -2129 & 0.973 \\
\hline \multicolumn{5}{|l|}{ Second year costs, $n=168$ : } \\
\hline Main cost components & $\begin{array}{l}\text { TMG } N=83 \\
\text { Mean CI }(95 \%)\end{array}$ & $\begin{array}{l}\text { CG } N=85 \\
\text { Mean CI }(95 \%)\end{array}$ & Incremental cost & $p$ \\
\hline Hospitalizations & $3532[2322 ; 5707]$ & $4740[3000 ; 8621]$ & -1208 & 0.494 \\
\hline Consultations & $750[562 ; 1204]$ & $811[641 ; 1187]$ & -61 & 0.368 \\
\hline Medical acts & $1187[907 ; 2032]$ & $1264[929 ; 1990]$ & -77 & 0.995 \\
\hline Paramedical act & $700[427 ; 1284]$ & $900[578 ; 1439]$ & -200 & 0.237 \\
\hline Medication & $2718[2173 ; 3733]$ & $3555[2820 ; 5116]$ & -837 & 0.338 \\
\hline Medical devices & $1537[1160 ; 2118]$ & $1342[982 ; 1847]$ & 195 & 1.000 \\
\hline Transportation & $226[111 ; 460]$ & $641[266 ; 1535]$ & -415 & 0.413 \\
\hline Daily allowance and disability pension & 0 & 0 & 0 & \\
\hline EDUC@DOM & 0 & 0 & 0 & \\
\hline Total & $10,650[8486 ; 15189]$ & $13,253[10052 ; 18318]$ & -2603 & 0.242 \\
\hline
\end{tabular}

Two-year costs, $n=168$ :

\begin{tabular}{lllrr}
\hline Main cost components & $\begin{array}{l}\text { TMG } \boldsymbol{N}=\mathbf{8 3} \\
\text { Mean CI }(\mathbf{9 5 \%})\end{array}$ & $\begin{array}{l}\text { CG } \boldsymbol{N = 8 5} \\
\text { Mean CI (95\%) }\end{array}$ & Incremental cost & $p$ \\
\hline Hospitalizations & $6799[4661 ; 10816]$ & $8631[6008 ; 13074]$ & -1832 & 0.219 \\
Consultations & $1190[910 ; 1687]$ & $1362[1048 ; 2016]$ & -172 & 0.193 \\
Medical acts & $1894[1423 ; 2788]$ & $2173[1552 ; 3450]$ & -279 & 0.587 \\
Paramedical act & $1021[608 ; 1823]$ & $1510[902 ; 2457]$ & -489 & 0.358 \\
Medication & $4707[3725 ; 6819]$ & $6854[4945 ; 10762]$ & -2147 & 0.198
\end{tabular}


Table 2 continued

\begin{tabular}{lllll}
\hline Two-year costs, $\boldsymbol{n}=\mathbf{1 6 8}$ : & & & & \\
\hline Main cost components & $\begin{array}{l}\text { TMG } \boldsymbol{N}=\mathbf{8 3} \\
\text { Mean CI } \mathbf{9 5 \% )}\end{array}$ & $\begin{array}{l}\text { CG } \boldsymbol{N}=\mathbf{8 5} \\
\text { Mean CI (95\%) }\end{array}$ & Incremental cost & $\boldsymbol{p}$ \\
\hline Medical devices & $2600[1944 ; 3553]$ & $2364[1743 ; 3614]$ & 236 & 0.735 \\
Transportation & $412[217 ; 771]$ & $1052[419 ; 3404]$ & -640 & 0.802 \\
Daily allowance and disability pension & $2550[1370 ; 4568]$ & $3343[1938 ; 5874]$ & -793 & 0.622 \\
EDUC@DOM & 1015 & 0 & 1015 & - \\
Total & $22,188[17309 ; 30346]$ & $27,289[21242 ; 38764]$ & -5101 & 0.528
\end{tabular}

$C G$ control group, $T M G$ telemonitoring group, $C I$ confidence interval, $p p$ value

Table 3 Adjustment models for the 1-year and 2-year periods, $n=256$

\begin{tabular}{|c|c|c|c|c|c|}
\hline \multirow[t]{2}{*}{ Variable } & \multirow[t]{2}{*}{ Modality } & \multicolumn{2}{|l|}{1 year } & \multicolumn{2}{|l|}{2 years } \\
\hline & & $\overline{\mathrm{RR}[\mathrm{CI}]}$ & $p$ value & $\overline{\mathrm{RR}[\mathrm{CI}]}$ & $p$ value \\
\hline \multirow[t]{2}{*}{ Age } & $<61$ year old & 1 & & 1 & \\
\hline & $\geq 61$ year old & $1.01[0.7 ; 1.47]$ & 0.9395 & $1.15[0.89 ; 1.48]$ & 0.2778 \\
\hline \multirow[t]{2}{*}{ Gender } & Women & 1 & & 1 & \\
\hline & Men & $0.87[0.64 ; 1.16]$ & 0.3443 & $0.93[0.7 ; 1.22]$ & 0.5851 \\
\hline \multirow[t]{2}{*}{ Groups } & Control & 1 & & 1 & \\
\hline & Telemonitoring & $0.79[0.58 ; 1.08]$ & 0.1452 & $0.79[0.61 ; 1.03]$ & 0.0879 \\
\hline \multirow[t]{2}{*}{ Obesity } & No & 1 & & 1 & \\
\hline & Yes & $1.58[1.15 ; 2.17]$ & 0.0067 & $1.60[1.2 ; 2.13]$ & 0.0026 \\
\hline \multirow[t]{2}{*}{ Insulin therapy } & No & 1 & & 1 & \\
\hline & Yes & $1.34[0.97 ; 1.86]$ & 0.0781 & $1.48[1.09 ; 2.03]$ & 0.0189 \\
\hline
\end{tabular}

$R R$ relative risk, $C I$ confidence interval

appropriate because the levels of effectiveness of the groups were not strictly equivalent. EDUC@DOM led to a $€ 1334$ cost saving and a $0.17 \%$ decrease in HbA1c over 1 year, and to a $€ 3144$ cost saving and a $0.14 \%$ decrease in HbA1c over 2 years. In the light of these results and the 95\% confidence ellipses for the 1- and 2-year periods on the CEP plane, it was concluded that EDUC@DOM is a cost-effective strategy with a high probability of being a dominant strategy. We observed a significantly higher prevalence of neuropathy in the CG. Due to the relatively small sample size, the randomization may not have smoothed out all of the differences between groups. Nevertheless, only a slight impact of neuropathy on cost management was found within the multivariate analysis, with no modification of the group effect when this variable was considered. Given the limited sample size, this variable was not considered a confounding factor in the final analysis. 
Table 4 Cost-effectiveness analysis for the 1-year and 2-year periods

\begin{tabular}{|c|c|c|c|c|c|}
\hline & Cost $(€)$ & $\begin{array}{l}\text { Effectiveness } \\
\text { (HbA1c) }\end{array}$ & $\begin{array}{l}\text { Incremental } \\
\text { cost }\end{array}$ & $\begin{array}{l}\text { Incremental HbA1c } \\
\text { decrease }\end{array}$ & ICER \\
\hline \multicolumn{6}{|c|}{ 1-year cost, effectiveness and ICER } \\
\hline CG & $\begin{array}{l}13,069[11,700 \\
15,137]\end{array}$ & $7.67[7.57 ; 7.75]$ & - & - & - \\
\hline TMG & $\begin{array}{l}11,735[10,337 ; \\
13,641]\end{array}$ & $7.50[7.41 ; 7.58]$ & -1334 & 0.17 & -7847 \\
\hline \multicolumn{6}{|c|}{ 2-year cost, effectiveness and ICER } \\
\hline CG & $\begin{array}{l}26,487[24,132 ; \\
29,817]\end{array}$ & $7.73[7.65 ; 7.83]$ & - & - & - \\
\hline TMG & $\begin{array}{l}23,343[21,007 ; \\
26,533]\end{array}$ & $7.59[7.50 ; 7.68]$ & -3144 & 0.14 & $-22,457$ \\
\hline
\end{tabular}

$C G$ control group, $T M G$ telemonitoring group, ICER incremental cost-effectiveness ratio

Precise cost-effectiveness evaluations of telemedicine or telemonitoring tools are sparse. In a systematic review performed in 2014, Zhai et al. [13] found that only two of 47 articles dealt with the costs in addition to the clinical efficacy of telemedicine intervention in T2D. These two papers focused on telephone- and internet-based interventions. The first only considered the costs of a telephone intervention and concluded that telephone monitoring was cost effective, with a low ICER of $\$ 490$ for a $1 \%$ decrease in HbA1c [31]. The second, using a Medicare database and a larger cost scope, compared intensive nurse case management via tele-visits to usual care [32]. Considering the significant cost of the intervention, over $\$ 8000$ per person per year, they calculated that the ICER was equal to $\$ 29,869$ for a $1 \%$ decrease in HbA1c [13]. In 2018, another systematic review assessed the cost-effectiveness of telemedicine in a diabetes-distinguishing telemonitoring device, tele-ophthalmology screening and telephone intervention. Just one study was found that focused on a telemonitoring device, underlining the crucial need for original research on the topic [33]. This paper notably assessed the cost-effectiveness of a TMG device in the German, Italian and Greek health care contexts. Finally, a 2020 study assessed, by simulation, the cost-utility of TMG for patients with T2D in Japan over 20 years [34]. Using a Markov model, this paper aimed to assess the effect of continuous glucose monitoring (CGM) on T2D management, taking into account the probability of transitioning to a related $\mathrm{T} 2 \mathrm{D}$ complication state. A \$33,039/QALY was found in favour of CGM app, which is under the Japanese acceptability threshold. Nevertheless, this study suffered from several limitations; in particular, the simulation model was based on an unmeasured values of the parameters and a lot of hypotheses. Finally, telemonitoring or telemedicine seems to lead to cost-effectiveness results, notably due to the prevention of complications due to better glycaemic control. In this context, the present study's results are consistent with the literature. The combination of telemonitoring and tele-education brings a supplemental improvement, with cost-saving results in addition to an improvement in effectiveness. T2D management using telemedicine devices must enforce tele-education in addition to glycaemic telemonitoring alone, particularly to promote an optimal patient lifestyle (physical activity and food).

Some limitations of this study must be acknowledged. The most apparent is the missing data on resource consumption due to the database coverage in addition to the patient living in a border region. Nevertheless, it was 

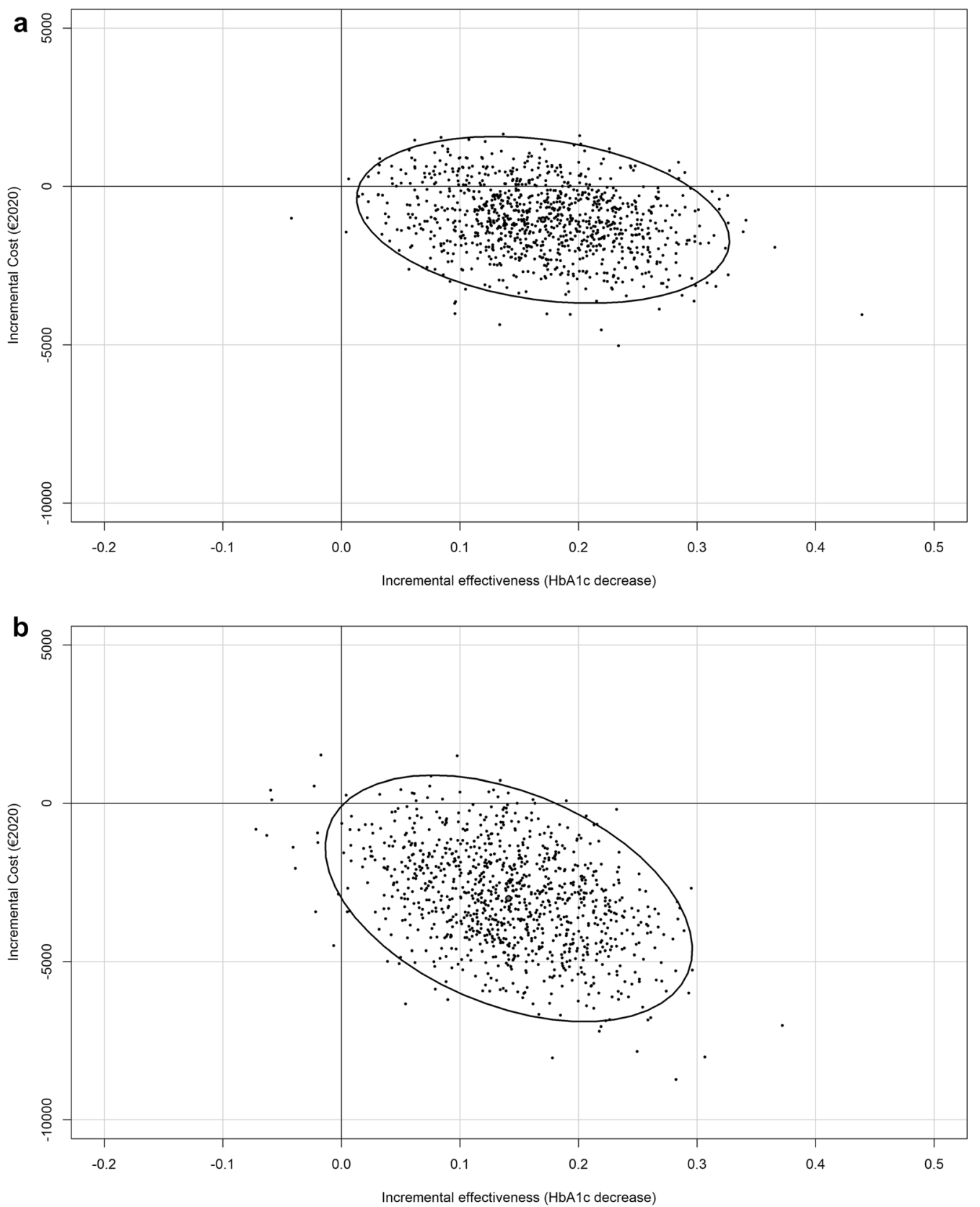

Fig. 1 a Incremental cost-effectiveness ratio and its 95\% confidence ellipse over a 1-year period. b Incremental costeffectiveness ratio and its $95 \%$ confidence ellipse over a 2 -year period

hypothesized that this did not impact the missingness mechanism. The distribution of patient characteristics was not drastically modified within the population with missing data. An appropriate imputation methodology and complementary analysis were then used, and are presented in an additional file. No critical differences in baseline patient characteristics were observed between participants with complete and incomplete data sets (Supplementary File 1). The cost-effectiveness assessment based on the available economic data makes it possible to check whether the results are potentially conflicted or not after the imputation (Supplementary File 2). In addition, drawing from the five imputed datasets allows the inter- 
imputation variability to be evaluated (Supplementary File 3). In this context, taking the missing economic data into account did not modify the conclusion that EDUC@DOM is either cost effective or a dominant strategy. Besides glycaemic control (i.e. the A1c level), which has been retained as the primary outcome for assessing the efficacy of the EDUC@DOM program, we must acknowledge that lifestyle intervention may have led to an improvement in the control of cardiovascular risk factors, mainly blood pressure and the lipid profile, which contributes greatly to preventing diabetes-related complications. Unfortunately, since the study design did not include standardized monitoring of these parameters, we were not able to reliably assess the multifactorial impact of the EDUC@DOM program. Another limitation is related to the short time horizon used to assess the 1-year intervention. The incremental Hb1Ac between controls and the TMG seemed to be less important over the second year, and it can be hypothesized that it would have continued to decrease in the third year, followed by a reduced cost-saving effect. This consideration further supports the need to use telemonitoring innovation with a long-term perspective. In addition, the usefulness of telemedicine depends on the patient's life course, so this kind of management has to be fully adaptable to the patient's life. As the economic study performed here relies on a secondary objective, the sample size was calculated based on the HbA1c clinical endpoint alone. This is a limitation of the economic study because of the large variation in the cost distribution and the unknown distribution of the ICER. Nevertheless, afterwards, we assessed the sample size needed using our study estimate and the formula of Glick et al., and found that sample sizes of 110 and 137 by arm were needed for the 1-year and 2-year periods, respectively [35]. Without the missing data, the sample sizes used are consistent with these estimates. As expected, a high inter-individual variability in cost distribution related to T2D management was observed. These important variations are hard to deal with, especially for a low sample size where the trend can mainly be observed. Nevertheless, patients with high costs are not outliers and have to be considered. This particularly highlights the need to use smoothed data from an adjustment model and to assess the variation in outcomes due to the imputation. Finally, clinical efficacy was found to be only at the boundary of statistical significance, with only a slight decrease in HbA1c-less than the $0.5 \%$ drop that is generally considered the clinically significant threshold. However, clinical efficacy and efficiency are different measurement tools with different aims. Efficiency measurement provides further information on whether healthcare resources are used to get the best value for money, while efficacy measurement determines whether an intervention produces the expected result under ideal circumstances [36]. Moreover, the healthcare resources used are directly linked with the efficacy in our context, as better glycaemic control is thought to lead to the prevention of diabetesrelated complications and to an improvement in overall health. In this context, it is felt that this does not change the legitimacy of the study, particularly given the need for economic data on telemonitoring devices.

\section{CONCLUSION}

Cost-effectiveness analyses primarily aim to provide complementary information that can help a decision-maker to choose one strategy over another. In this context, the present study provides crucial information about the cost and cost-effectiveness of telemonitoring during and following EDUC@DOM use. Given the observed slight HbA1c decrease and cost decrease of borderline significance, and according to the 95\% confidence ellipses, the present data demonstrate that the EDUC@DOM program is cost effective and potentially a dominant strategy, particularly over a 2-year period.

\section{ACKNOWLEDGEMENTS}

Funding. This study was funded by the French Ministry of Health [call for projects for research programmes on the performance of the 
healthcare system (PREPS 2012 No. 12-0180078)] and the Midi-Pyrénées Regional Council [Call for Projects for Research on Clinical Transfer and Standardization in Bio-health 2012, year 1 (No. 11052617) and year 2 (No. 13050630)] for the development of the study methodology, data collection, data analysis and interpretation and the publication of the results. We are grateful to the SANOFI Laboratory for its participation and provision of blood glucose monitors. The Rapid Service Fee was funded by The University Hospital Center of Toulouse.

Authorship. All of the named authors meet the International Committee of Medical Journal Editors' (ICMJE) criteria for authorship for this article, take responsibility for the integrity of the work as a whole, and have given their approval for this version to be published.

Authorship Contributions. M.C. Turnin, S. Schirr-Bonnans and JC Buisson contributed to the concept and design of the study. M.C. Turnin, P. Gourdy, J. Martini, M.C. Chauchard, M.F. Poncet, V. Cosma, S. Lablanche, M. Coustols-Valat, L. Chaillous, C. Thivolet, C. Sanz, A. Penfornis, J. Delaunay, S. Schirr-Bonnans and S. Taoui participated in the recruitment and follow-up of patients enrolled in the study. Material preparation, data collection and analysis were performed by Mounie Michael, Costa Nadège, Benoît Lepage, Hélène Colineaux, J.M. Lagarrigue and $\mathrm{H}$. Roussel. The first draft of the manuscript was written by Mounie Michael and all authors commented on previous versions of the manuscript. All authors have read and approved the final manuscript.

Medical Writing, Editorial, and Other Assistance. We are very grateful to all patients who participated in this study. We also wish to extend our grateful thanks to the clinical teams at the University Hospital Centres of Grenoble, Lyon, Nantes and Nîmes, the Hospital Centres of Cahors, Corbeil-Essonne, Lannemezan and Tarbes, the Ambroise-Paré (Toulouse), Claude Bernard (Albi) and Pasteur (Toulouse) clinics and our 2 colleagues working in private practices. The EDUC@DOM study group includes all investigators involved in the study: Pr. P.Y. Benhamou (CHU de Grenoble - University Hospital Centre), Dr M. Rodier (CHU de Nîmes), Dr F. Ayon and Dr F. Puel-Olivier (Cahors Hospital Centre), Dr S. Fontaine (Hôpital Ducuing-Toulouse), Dr M. Perron (Lannemezan Hospital Centre), Dr J. Arrivié (Tarbes Hospital Centre), Dr F. Cousty-Pech (Clinique AmbroiseParé-Toulouse), Dr C. Rouby (Clinique PasteurToulouse), Dr F. Lafon (General practitioner, Toulouse), Dr I. Moura (Diabetologist, Gaillac). The manuscript has been reviewed by a professional translator, native British English speaker, specialized in medical field.

Disclosures. Marie-Christine Turnin has received congress invitations and consultancy fees from VitalAire/Air Liquide Health, Eli Lilly, and Sanofi. Pierre Gourdy has received advisory board and speaker honoraria from Abbott, Amgen, AstraZeneca, Novo Nordisk, Boehringer Ingelheim, Eli Lilly, Merck Sharp \& Dohme, Mundipharma, Sanofi, and Servier. Jacques Martini has nothing to disclose. Jean-Christophe Buisson has nothing to disclose. MarieChristine Chauchard has nothing to disclose. Jacqueline Delaunay has received congress invitations and consultancy fees from Sanofi. Solène Schirr-Bonnans has nothing to disclose. Soumia Taoui has nothing to disclose. MarieFrance Poncet has nothing to disclose. Valeria Cosma has nothing to disclose. Sandrine Lablanche has nothing to disclose. Magali Coustols-Valat has nothing to disclose. C Thivolet has received travel support for meetings, speaker fees and honoraria from Abbott Diabetes Care, Janssen, Lilly, Novo-Nordisk, Medtronic, Roche Diabetes Care, and Sanofi and is an advisory board member for Insulet and Medtronic. Caroline Sanz has nothing to disclose. Alfred Penfornis has nothing to disclose. Benoît Lepage has nothing to disclose. Hélène Colineaux has nothing to disclose. Michaël Mounié has nothing to disclose. Nadège Costa has nothing to disclose. Laurent Molinier has nothing to disclose. Henri Roussel has nothing to disclose. Jean-Marc Lagarrigue has nothing to disclose. Hélène Hanaire has received congress invitations, honoraria and consultancy fees from Abbott, Animas/Johnson \& Johnson, 
Medtronic, Roche, Eli Lilly, Novo Nordisk and MSD, and served on advisory board panels for Diabeloop and Insulet.

Compliance with Ethics Guidelines. All type 2 diabetes patients participating in this research received verbal and written information and were given the opportunity to ask any questions to help them understand the study. They signed a voluntary informed consent form before the research began. This study was submitted to the South-West and French Overseas Territories' Research Ethics Committee and received a favourable opinion from the REC on $27 / 05 / 2013$. This study was performed in accordance with the Helsinki Declaration of 1964 and its later amendments.

Data Availability. The datasets generated and/or analysed during the current study are available from the corresponding author upon reasonable request.

Open Access. This article is licensed under a Creative Commons Attribution-NonCommercial 4.0 International License, which permits any non-commercial use, sharing, adaptation, distribution and reproduction in any medium or format, as long as you give appropriate credit to the original author(s) and the source, provide a link to the Creative Commons licence, and indicate if changes were made. The images or other third party material in this article are included in the article's Creative Commons licence, unless indicated otherwise in a credit line to the material. If material is not included in the article's Creative Commons licence and your intended use is not permitted by statutory regulation or exceeds the permitted use, you will need to obtain permission directly from the copyright holder. To view a copy of this licence, visit http://creativecommons.org/licenses/by$\mathrm{nc} / 4.0 /$.

\section{REFERENCES}

1. Davies MJ, D'Alessio DA, Fradkin J, et al. Management of hyperglycemia in type 2 diabetes, 2018. A consensus report by the American Diabetes Association (ADA) and the European Association for the Study of Diabetes (EASD). Diabetes Care. 2018;2018(41):2669-701.

2. Marina T, Silvia G, Luigi G, Giorgio G, Valerio M, Gabriel M, Pietro P, Laura T, Marco T, Piervincenzo B, Franco C, Massimo P. Rethink Organization to iMprove Education and Outcomes (ROMEO)-a multicenter randomized trial of lifestyle intervention by group care to manage type 2 diabetes. Diabetes Care. 2010;33:745-7.

3. Zhang ZY, Miao LF, Qian LL, Wang N, Qi MM, Zhang YM, Dang SP, Wu Y, Wang RX. Molecular mechanisms of glucose fluctuations on diabetic complications. Front Endocrinol (Lausanne). 2019;18(10):640. https://doi.org/10.3389/fendo. 2019.00640 .

4. The Diabetes Control and Complications Trial Research Group. The effect of intensive treatment of diabetes on the development and progression of long-term complications in insulin-dependent diabetes mellitus. N Engl J Med. 1993;329:997-1086.

5. UK Prospective Diabetes Study (UKPDS) Group. Intensive blood glucose control with sulphonylureas or insulin compared with conventional treatment and risk of complications in patients with type 2 diabetes (UKPDS 33). Lancet 1998;352: 837-53.

6. Deshpande AD, Harris-Hayes M, Schootman M. Epidemiology of diabetes and diabetes-related complications. Phys Ther. 2008;88(11):1254-64. https://doi.org/10.2522/ptj.20080020.

7. Kulzer B, Daenschel W, Daenschel I, Schramm W, Messinger D, Weissmann J, et al. Integrated personalized diabetes management improves glycemic control in patients with insulin-treated type 2 diabetes: results of the PDM-ProValue study program. Diabetes Res Clin Pract. 2018;144:200-12.

8. Diabetes Control and Complications Trial Research Group. The effect of intensive treatment of diabetes on the development and progression of long-term complications in insulin-dependent diabetes mellitus. N Engl J Med. 1993;329:997-1086.

9. UK Prospective Diabetes Study (UKPDS) Group. Intensive blood glucose control with sulphonylureas or insulin compared with conventional treatment and risk of complications in persons with type 2 diabetes (UKPDS 33). Lancet 1998;352: 837-53.

10. Lee PA, Greenfield G, Pappas Y. The impact of telehealth remote patient monitoring on glycemic control in type 2 diabetes: a systematic review and meta-analysis of systematic reviews of randomised 
controlled trials. BMC Health Serv Res. 2018;18(1): 495. https://doi.org/10.1186/s12913-018-3274-8.

11. Lee JY, Lee SWH. Telemedicine cost-effectiveness for diabetes management: a systematic review. Diabetes Technol Ther. 2018;20(7):492-500. https://doi.org/10.1089/dia.2018.0098 (Epub 2018 May 29).

12. Tsuji S, Ishikawa T, Morii Y, Zhang H, Suzuki T, Tanikawa T, Nakaya J, Ogasawara K. Cost-effectiveness of a continuous glucose monitoring mobile app for patients with type 2 diabetes mellitus: analysis simulation. J Med Internet Res. 2020;22(9): e16053.

13. Zhai YK, Zhu WJ, Cai YL, Sun DX, Zhao J. Clinicaland cost-effectiveness of telemedicine in type 2 diabetes mellitus: a systematic review and metaanalysis. Medicine. 2014;93(28):e312. https://doi. org/10.1097/MD.0000000000000312.

14. Andersson E, Persson S, Hallén N, et al. Costs of diabetes complications: hospital-based care and absence from work for 392,200 people with type 2 diabetes and matched control participants in Sweden. Diabetologia. 2020;63:2582-94. https://doi. org/10.1007/s00125-020-05277-3.

15. Stegbauer C, Falivena C, Moreno A, et al. Costs and its drivers for diabetes mellitus type 2 patients in France and Germany: a systematic review of economic studies. BMC Health Serv Res. 2020;20:1043. https://doi.org/10.1186/s12913-020-05897-w.

16. Schirr-Bonnans S, Costa N, Derumeaux-Burel H, Bos J, Lepage B, Garnault V, Martini J, Hanaire H, Turnin MC, Molinier L. Cost of diabetic eye, renal and foot complications: a methodological review. Eur J Health Econ. 2017;18(3):293-312. https://doi. org/10.1007/s10198-016-0773-6 (Epub 2016 Mar 14).

17. Turnin MC, Gourdy P, Martini J, Buisson JC, Chauchard MC, Delaunay et al. Educ@dom Study Group. Impact of a remote monitoring programme including lifestyle education software in type 2 diabetes: results of the Educ@dom randomised multicentre study. Diabetes Ther. 2021. https://doi. org/10.1007/s13300-021-01095-X.

18. Turnin MC, Schirr-Bonnans S, Martini J, Buisson JC, Taoui S, Chauchard MC, Costa N, Lepage B, Molinier L, Hanaire H. Educ@dom: comparative study of the telemonitoring of patients with type 2 diabetes versus standard monitoring-study protocol for a randomized controlled study. Diabetol Metab Syndr. 2017;11(9):52. https://doi.org/10. 1186/s13098-017-0252-y.

19. Buisson JC. Nutri-Educ, a nutrition software application for balancing meals, using fuzzy arithmetic and heuristic search algorithms. Artif Intell Med. 2008;42:213-27.

20. Buisson JC, Garel A. Balancing meals using fuzzy arithmetic and heuristic search algorithms. IEEE Trans Fuzzy Syst. 2003;11:68-78.

21. Turnin MC, Beddok R, Clottes $\mathrm{J}$, et al. Telematic expert system DIABETO. New tool for diet selfmonitoring for diabetic patients. Diabetes Care. 1992;15:204-12.

22. Turnin MC, Bolzonella Pene C, Dumoulin S, et al. Multicenter evaluation of the Nutri-Expert Telematic System in diabetic patients. Diabete Metab. 1995;21:26-33.

23. Turnin MC, Bourgeois $\mathrm{O}$, Cathelineau $\mathrm{G}$, et al. Multicenter randomized evaluation of a nutritional education software in obese patients. Diabetes Metab. 2001;27:139-47.

24. Bezin J, Duong M, Lassalle R, Droz C, Pariente A, Blin P, Moore N. The national healthcare system claims databases in France, SNIIRAM and EGB: powerful tools for pharmacoepidemiology. Pharmacoepidemiol Drug Saf. 2017;26(8):954-62. https://doi.org/10.1002/pds.4233 (Epub 2017 May 24).

25. Moulis G, Lapeyre-Mestre M, Palmaro A, Pugnet G, Montastruc J-L, Sailler L. French health insurance databases: what interest for medical research? Rev Med Interne. 2015;36(6):411-7.

26. Drummond MF, Sculpher MJ, Torrance GW, O'Brien BJ, Stoddart GL. Methods for the economic evaluation of health care programmes. Oxford: Oxford University Press; 2005. p. 379.

27. Barber JA, Thompson SG. Analysis of cost data in randomized trials: an application of the non-parametric bootstrap. Stat Med. 2000;19(23):3219-36.

28. Morris TP, White IR, Royston P. Tuning multiple imputation by predictive mean matching and local residual draws. BMC Med Res Methodol. 2014;14: 75. https://doi.org/10.1186/1471-2288-14-75.

29. Black WC. The CE plane: a graphic representation of cost-effectiveness. Med Decis Mak. 1990;10(3): 212-4.

30. Cohen DJ, Reynolds MR. Interpreting the results of cost-effectiveness studies. J Am Coll Cardiol. 2008;52(25):2119-26.

31. Schechter CB, Cohen HW, Shmukler C, Walker EA. Intervention costs and cost-effectiveness of a successful telephonic intervention to promote diabetes control. Diabetes Care. 2012;35(11):2156-60. 
https://doi.org/10.2337/dc12-0048 (Epub 2012 Jul 30).

32. Moreno L, Dale SB, Chen AY, Magee CA. Costs to Medicare of the Informatics for Diabetes Education and Telemedicine (IDEATel) home telemedicine demonstration: findings from an independent evaluation. Diabetes Care. 2009;32(7):1202-4. https://doi.org/10.2337/dc09-0094 (Epub 2009 Apr 14).

33. Dafoulas GE, Mavrodi A, Bargiota A, Giannakakos $\mathrm{H}$, Stafylas P, Gkiata P, et al. Cost utility analysis of long-term telemonitoring of patients with DMT2: Results of the Greek pilot of the renewing health multicenter pragmatic randomized trial. Int J Integr Care. 2014;14:8. https://doi.org/10.5334/ijic.1767.
34. Tsuji S, Ishikawa T, Morii Y, Zhang H, Suzuki T, Tanikawa T, Nakaya J, Ogasawara K. Cost-effectiveness of a continuous glucose monitoring mobile app for patients with type 2 diabetes mellitus: analysis simulation. J Med Internet Res. 2020;22(9): e16053. https://doi.org/10.2196/16053.PMID: 32940613.

35. Glick HA. Sample size and power for cost-effectiveness analysis (part 1). Pharmacoeconomics. 2011;29(3):189-98. https://doi.org/10.2165/ 11585070-000000000-00000.

36. lo-Storto C, Goncharuk AG. Efficiency vs effectiveness: a benchmarking study on European healthcare systems. Econ Soc. 2017;10(3):102-15. 